\title{
Treatment of glenohumeral instability in rugby players
}

\author{
Lennard Funk ${ }^{1}$
}

Received: 1 November 2015 / Accepted: 23 December 2015 / Published online: 19 January 2016

(C) The Author(s) 2016. This article is published with open access at Springerlink.com

\begin{abstract}
Rugby is a high-impact collision sport, with impact forces. Shoulder injuries are common and result in the longest time off sport for any joint injury in rugby. The most common injuries are to the glenohumeral joint with varying degrees of instability. The degree of instability can guide management. The three main types of instability presentations are: (1) frank dislocation, (2) subluxations and (3) subclinical instability with pain and clicking. Understanding the exact mechanism of injury can guide diagnosis with classical patterns of structural injuries. The standard clinical examination in a large, muscular athlete may be normal, so specific tests and techniques are needed to unearth signs of pathology. Taking these factors into consideration, along with the imaging, allows a treatment strategy. However, patient and sport factors need to be also considered, particularly the time of the season and stage of sporting career. Surgery to repair the structural damage should include all lesions found. In chronic, recurrent dislocations with major structural lesions, reconstruction procedures such as the Latarjet procedure yields better outcomes. Rehabilitation should be safe, goal-driven and athlete-specific. Return to sport is dependent on a number of factors, driven by the healing process, sport requirements and extrinsic pressures.
\end{abstract}

\section{Level of evidence $\mathrm{V}$.}

Keywords Rugby · Shoulder · Instability · Sport · Collision

Lennard Funk

lenfunk@shoulderdoc.co.uk

1 Upper Limb Unit, Wrightington Hospital, Hall Lane, Appley Bridge WN6 9EP, UK

\section{Introduction}

Rugby is the ninth most popular sport in the world, developed in England and now widely played in France where it has a strong tradition in the Basque, Occitan and Catalan people along the border regions between Spain and France. The game is very popular in South Africa, Australia and New Zealand. It has spread thence to much of Polynesia, having particularly strong followings in Fiji, Samoa and Tonga. Rugby is gaining popularity in Europe, South and North America. It is a high collision sport, with the highest incidence of traumatic injuries of all sports [13, 35]. Shoulder injuries are second to knee injuries, but result in the longest period out of play compared to any other injury [11]. As rugby players get larger and faster, the impacts involved have increased, despite changes in the rules to try to limit serious injuries [17]. It has been shown that the forces in modern-day rugby are in excess of $10 \mathrm{Gs}$, equivalent to low-impact motor vehicle accidents. This has led to more serious injuries than before, sometimes life-threatening. In the shoulder, varying degrees of instability are very common. These range from painful subclinical micro-instability to complete fracture-dislocations of the glenohumeral joint [16]. The direction of instability may be anterior, posterior, inferior or combined with a complex array of pathologies [10].

\section{Aetiology}

The most common mechanism of shoulder injury is due to the tackling event [5]. Injuries can occur to the tackler or the ball carrier [18]. Video analysis studies have shown that the common mechanisms of injury result in predictable patterns of shoulder pathology. This information is useful in 
Fig. 1 Common mechanism of shoulder injury in rugby and the structural injuries [10]

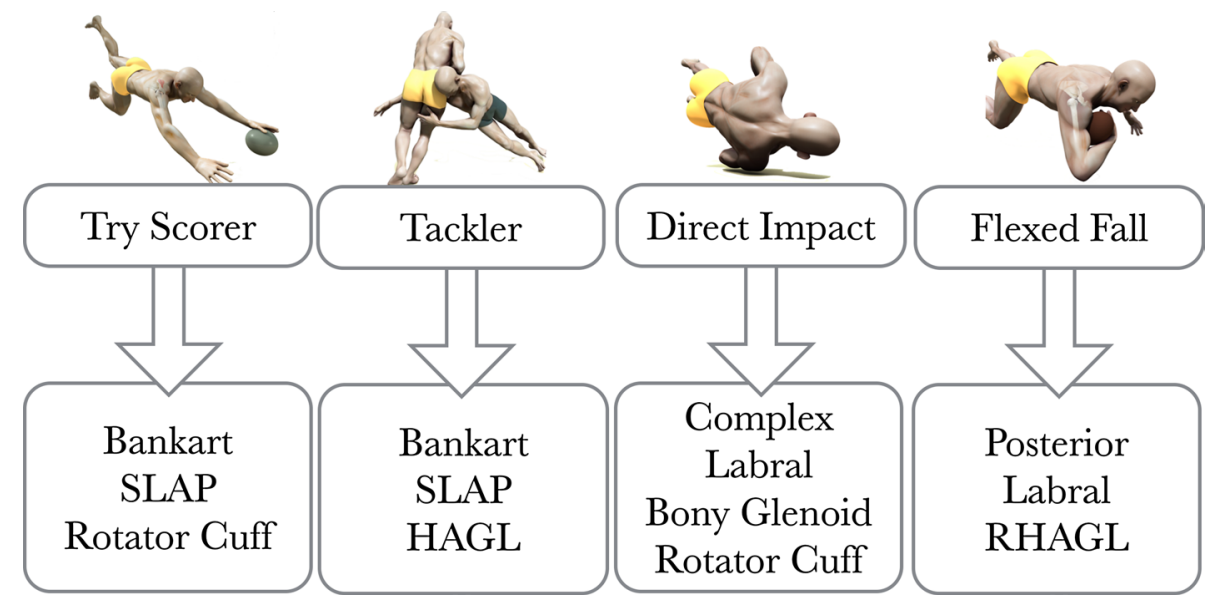

understanding the expected injuries prior to investigations. The common mechanism of injury are the tackle, 'tryscorer', direct impact and flexed fall [10].

\section{Tackler injury}

This occurs most commonly when the player tackles an opponent travelling towards them. The arm is held abducted to ninety degrees. A posteriorly directed force results from contact with the ball carrier. The tacklers' arm extends behind the player in the plane of abduction, exerting a levering force on the glenohumeral joint.

Anterior dislocation is most common in tacklers, with a high incidence of anterior-inferior labral tears, SLAP tears and Hill-Sachs lesions. Humeral avulsions of the anterior band of the inferior glenohumeral ligament (HAGL) tend to be more common in tackling injuries. We have also found an increasing incidence of bony Bankart lesions recently [10].

\section{Try-scorer injury}

This mechanism occurs whilst diving and reaching the ball-carrying hand forward to score a try. The mechanism involves the injured arm in extreme overhead flexion above $90^{\circ}$. A posterior force drives the arm backwards and exerts leverage on the glenohumeral joint with the arm either remaining in fixed flexion by contact with the ground or forced into further hyper-flexion. This may be compounded by opposing players falling on top of the injured player, increasing the leverage on the glenohumeral joint.

The glenohumeral joint may subluxate or dislocate, resulting in Bankart tears, Hill-Sachs lesions and rotator cuff tears. This mechanism has a higher incidence of significant rotator cuff tears than the others [10].

\section{Direct impact injury}

The ball carrier may impact directly with the ground or another player, sustaining a large impact to the lateral aspect of the shoulder. The arm is held flexed below ninety degrees or neutral, with internal rotation, such as when carrying a ball by the side. A medially directed compressive force caused by direct impact to the shoulder results in injury.

Due to the variability of the exact impact vector, multiple complex injuries are sustained. This includes a combination of bony glenoid lesions, complex labral tears, scapula fractures and acromio-clavicular joint (ACJ) injuries.

\section{Flexed fall injury}

In rugby league, increasingly in modern rugby union, the ball carrier is tackled and lifted from behind. The ballcarrying elbow makes the first impact with the ground, with the elbow and shoulder joints flexed whilst holding the ball. This results in a large posterior directed force through the glenohumeral joint, causing injury and disruption to the posterior shoulder structures. The common pathologies are posterior labral tears, reverse bony Bankart lesions, reverse HAGL tears and posterior rotator cuff injuries (Fig. 1).

\section{Diagnosis}

Instability in rugby players presents with a myriad of symptoms. It is easy to make the diagnosis where there has been frank dislocations and ongoing feelings of instability or recurrent dislocations. However, this is not often the case. Since $60-70 \%$ of shoulder stability is muscular, most rugby players only get symptoms with extreme forces and activities due to their excellent abilities to compensate 
with their strong shoulder musculature. The usual clinical tests for instability may all be normal. A focused and thorough history and examination, tailored to the athlete, are required. There are a few common presentations of instability in the rugby player, which can be classified as: (1) frank dislocation requiring relocation, (2) subluxation and (3) subclinical instability.

\section{Frank dislocation/dislocator}

In this presentation, there is a definite report of shoulder dislocation, requiring relocation. Nowadays, most athletes present to the specialist after the first dislocation. It is imperative to know the exact mechanism of injury, as this will intimate the probable pathologies. The ease of relocation, method and sedation will also intimate the probable pathologies. The more difficult the relocation, the more significant the pathology. Lesions such as bony Bankart fractures, HAGL tears and rotator cuff tears should be expected.

\section{Subluxation(s)}

The player will have had single or recurrent episodes of true subluxations. They report that they felt their shoulder "slip out and then back in" on impact or tackle. It is important to ascertain the mechanism, for direction, and also the force of injury. The force of injury reflects the severity of pathology and also may reflect underlying hyperlaxity. Feelings of a temporary 'dead arm' at the time of injury, similar to neurogenic stingers, are commonly reported.

\section{Subclinical instability}

An injury may result in severe pain and 'dead arm', but no true dislocation or subluxation. The player may be able to continue the match, with severe post-match pain. They may be able to return to play, but sustain repeated episodes of pain and 'dead arm' with tackles and impact. Many are able to play through the season, but struggle with weight training, particularly pressing and overhead exercises. Painful clicking, clunking or popping from the joint are frequent.

\section{Clinical examination}

If the patient presents within a few days of the initial injury, the examination is often limited by pain. Injecting the joint with local anaesthesia may assist the examination procedure and relieve pain. It is essential to assess the neuromuscular status, particularly the axillary nerve. ACJ assessment is important as this may be an associated injury or an exacerbation.
Later presentations are easier to examine, but often many of the standard instability tests are less reliable in large muscular athletes. In addition to the usual range of motion and rotator cuff strength tests, the following clinical tests are also useful:

1. Anterior instability

(a) Anterior apprehension test [42] Often best performed with the patient seated or supine. The arm is brought gently and gradually into increasing range of abduction and external rotation. Rugby players often do not feel true apprehension, but may report 'stretching' and posterior pain (possibly from the bruised posterior humeral head impinging on the glenoid). Jobe's relocation manoeuvre is often negative.

(b) Antero-inferior apprehension sulcus The patient is asked to bend forward at the waist by about $30^{\circ}$ and the arm dangling down. Downward traction on the arm can reproduce anxiety, discomfort or apprehension. This indicates antero-inferior instability and can be performed in varying positions to indicate the direction of antero-inferior instability.

2. Posterior instability

(a) Wrightington posterior instability test (WPIT) [31] Posterior instability can be difficult to diagnose in large, muscular athletes. The usual posterior instability tests (Jerk and posterior apprehension tests) are only positive in patients with gross posterior instability. The patient's arm is positioned in flexion and full adduction with internal rotation. The scapula is fixed. The patient is then asked to resist downward pressure at the wrist. Inability to maintain the flexion against resistance with posterior shoulder pain is a positive test for subtle posterior instability. This is different to a positive O'Brein's test where there is anterior shoulder pain suggestive of a SLAP tear. The weakness is probably due to posterior translation of the humeral head and posterior cuff inhibition in full internal rotation and adduction of the shoulder.

(b) Kim's test [21] This is useful for overt posterior instability. With the patient seated, the arm is held by the examiner in a position of $90^{\circ}$ abduction. The arm is brought into flexion and internal rotation with the examiner applying an axial load by pushing on the flexed elbow and with the other hand pushing the upper arm posteriorly. Posterior shoulder pain denotes a positive test. 
3. Labral tears

(a) Modified dynamic labral shear test [20] This is a useful, non-specific test for detecting possible labral tears in athletes. The arm is brought into abduction and loaded axially through the flexed elbow. Whilst maintaining axial load, the shoulder is circumducted. A positive painful click or clunk is suggestive of a labral tear.

4. Laxity

(a) Glenohumeral laxity This should be assessed using the load-and-shift tests [11] in anterior, posterior and inferior (sulcus) directions, comparing to the opposite shoulder. The Gagey inferior laxity test [15] is also useful for any abnormal inferior capsular laxity.

(b) Generalised laxity The Beighton score [4] is used to determine the degree of generalised ligamentous joint laxity. A score above $6 / 9$ is indicative of generalised hypermobility, even in a large, muscular athlete.

\section{Investigations}

In the acute setting, radiographs are useful to diagnose any overt bony injuries; otherwise, an MRI scan within $24 \mathrm{~h}$ of the acute injury is useful to show most major soft tissue pathologies. Where there is blood in the glenohumeral joint, an arthrogram is not required. If unsure, an ultrasound scan may show a joint effusion, confirming blood in the joint (Fig. 2).

After $24 \mathrm{~h}$ from the acute injury, an MR arthrogram is generally the investigation of choice. It should show all major bony and soft tissue injuries. In addition to the standard sequences, additional fat-suppression sequences in the coronal plane and bone-enhancing $\mathrm{T} 1$ sequences in the axial and sagittal-oblique planes should be included. The fat-suppression sequences highlight any bone oedema, particularly around the ACJ and posterior humeral head. Boneenhancing $\mathrm{T} 1$ sequences are helpful to diagnose small bony glenoid injuries that can often be missed and negate the need for a CT scan. ABER (Abduction external rotation) sequences are also useful to highlight labral and partialthickness rotator cuff tears, as long as the patient is able to raise their arm overhead comfortably.

A CT arthrogram can be performed instead of an MR arthrogram. Traditionally, this is reported as being better for detecting bony lesions. CT scans are useful for any complex bony pathology (Fig. 3).

\section{Management}

Management decisions in professional athletes are often stressful for all concerned. The athlete feels vulnerable and naturally concerned about their career. The club and national team are anxious about the athletes return to sport, and the team clinicians have a huge burden of responsibility. The surgeon's role is to appreciate these issues in addition to managing the injury, based on their experience and knowledge of the published evidence. The clinical findings and imaging form a basis for the decision-making, but it is important to realise that these are a 'snapshot in time', and the patient's functional ability to perform and pain are the key determinants on the degree of intervention needed.

The frequency, aetiology, direction, severity (FEDS) classification system highlight the factors to consider when deciding on surgery for shoulder instability [25]. Lebus et al. [25] showed that aetiology and increased frequency of instability are the strongest predictors for requiring surgical stabilisation. My algorithm for managing a rugby player, or any other athlete, is based on three factors:

1. Type of instability—frank dislocation(s), subluxation(s) or subclinical instability

2. Severity of structural, pathological injury-e.g. undisplayed labral tear versus large bony Bankart lesion

3. Time of season and career

1. Type of instability

\subsection{Frank dislocation/dislocator}

In a rugby player with a frank dislocation, significant injuries are often sustained due to the forces required to dislocate a large, muscular shoulder. It is also recognised that the recurrence rate following true dislocations in elite, contact athletes is high $[1,22,32]$. This is reduced significantly with surgical stabilisation $[8,24,26,29]$.

1.2. Subluxation(s)

The majority of athletes in this group are often able to return to play with little lost time from competition after a subluxation 'instability event' [12]. The structural injuries are generally less severe than a complete dislocation. Dickens et al. [12] showed that almost one-third of athletes complete the season without any instability episodes. Therefore, inseason surgery for this group is often not needed, depending on their pain and functional ability. 

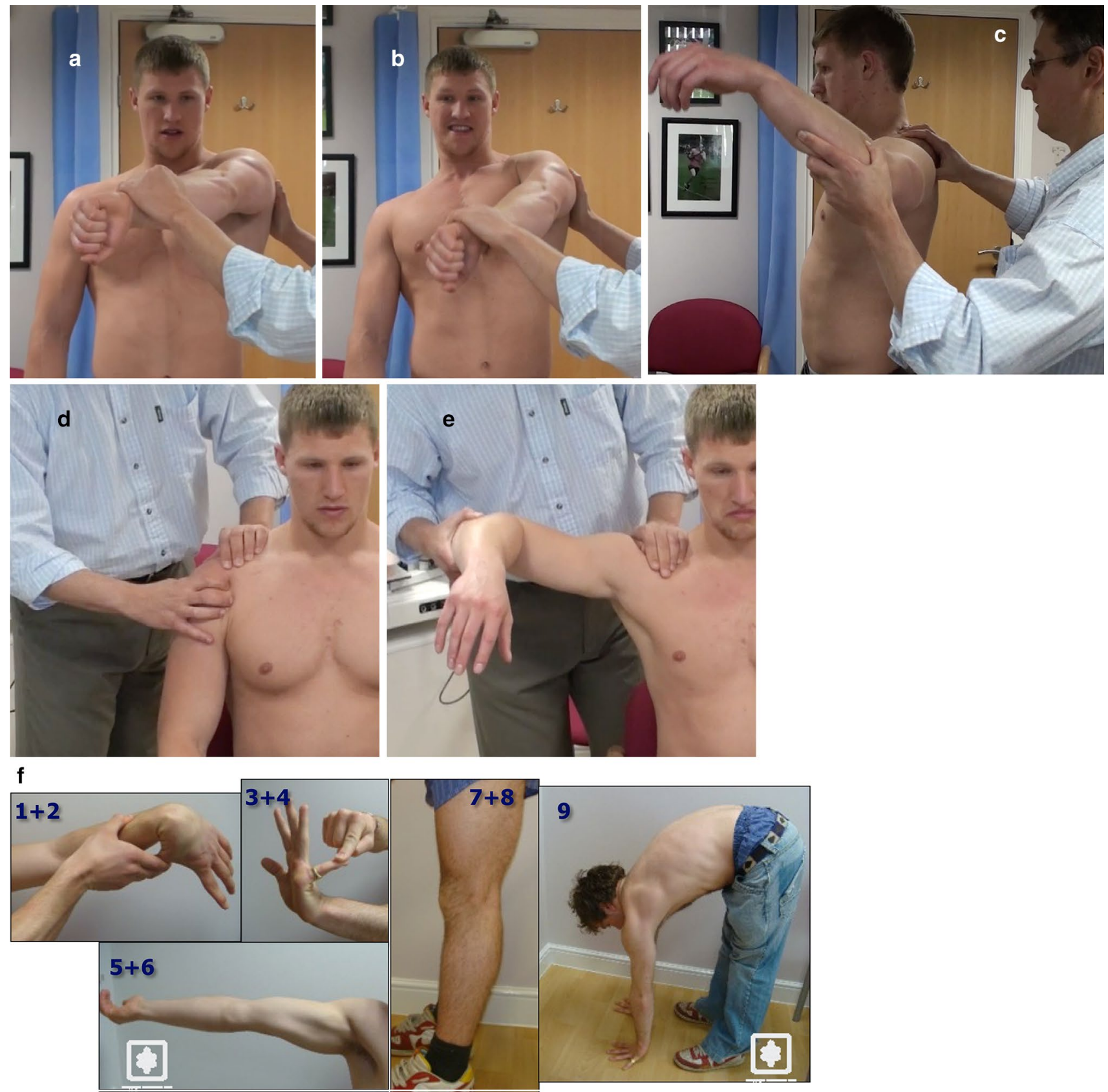

Fig. 2 Useful clinical tests for rugby players: a and b WPIT (Wrightington posterior instability test) [31]: inability to maintain the arm in flexion and adduction against resistance with the scapula corrected. c Modified dynamic labral shear test [20] for labral tears. Axial load

\subsection{Subclinical instability}

As with subluxations, these are 'instability events' that often do not prevent play. There is usually less severe structural injuries sustained. Although immediate surgery is not often required, progressive re-injury and progression of structural damage may require surgical repair when the athlete becomes functionally affected. applied whilst circumducting the arm. d Load-and-shift tests [41] for glenohumeral joint laxity. e Gagey test for inferior capsular laxity [15]. f Components of the Beighton score [4] on a young rugby player

2. Structural injury

The amount of glenohumeral joint damage is related to the risk of recurrence, with more significant lesions associated with higher risk of recurrence and a reduced ability to return to sport without surgical correction $[30,36]$. These significant 'major' lesions are bony Bankart injuries, HAGL tears, large Hill-Sachs lesions and full-thickness rotator cuff tears. Any of these inju- 

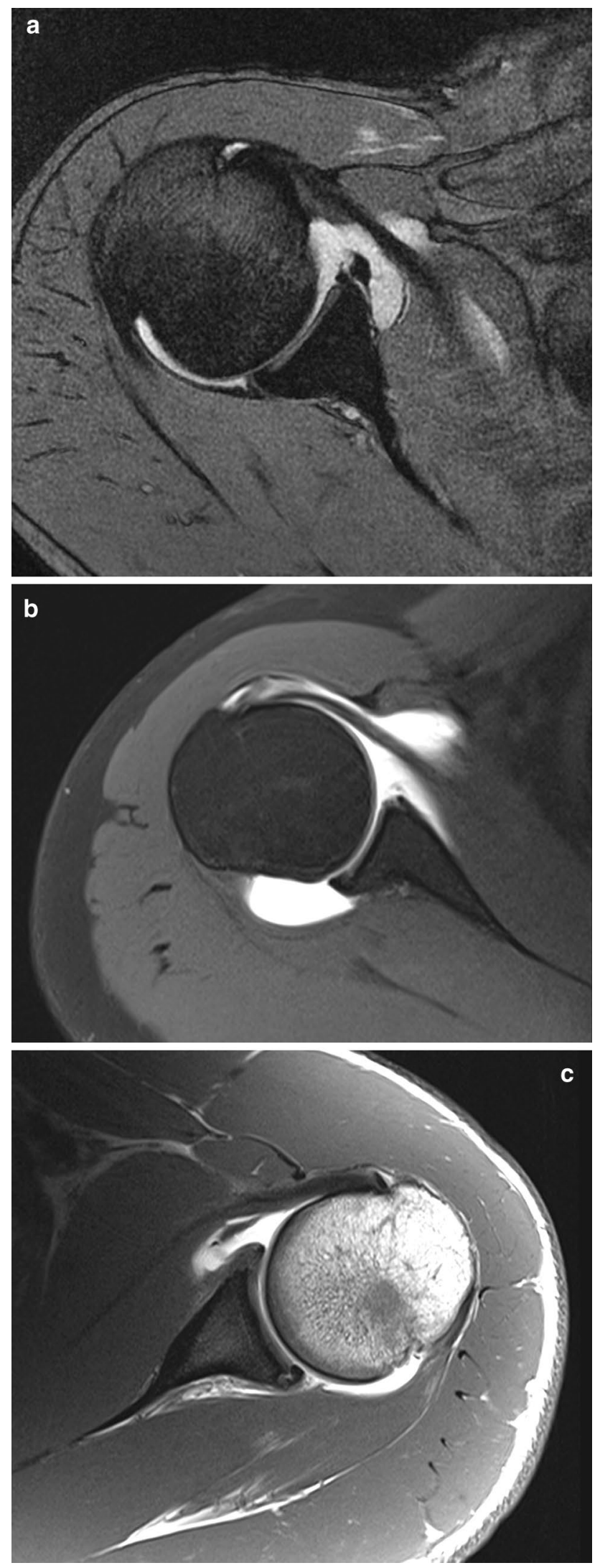

4Fig. 3 MR arthrogram images of labral injuries in rugby players, showing a a displaced anterior labral Bankart tear, $\mathbf{b}$ anterior bony glenoid lesion and $\mathbf{c}$ posterior labral tear

ries would suggest a reduced ability to return to sport without surgical stabilisation and a high risk of recurrence $[30,37]$.

'Minor lesions' are often not associated with true dislocations and are less severe. These include isolated labral tears, partial-thickness rotator cuff tears and small HillSachs lesions. However, hyperlaxity should be considered, as a hyperlax athlete may have a higher predisposition to re-injury with minor lesions [7, 39] (Table 1).

3. Timing

The aim of treatment is to return the athlete back to sport as soon and as safely as possible, without jeopardising their long-term prognosis. There is contradictory evidence to suggest that surgery either increases or reduces the long-term risk of shoulder joint degeneration. Therefore, the primary aim of treatment is to treat the patient's pain and functional limitations. It is often quicker to return an athlete to play without surgery for minor lesions without true dislocations $[6,12,30,37]$. However, it is probably unsafe to do so for major lesions with true dislocations. Therefore, my approach is to offer inseason surgery to the latter group and try return to play in the former group, whilst taking into account the type on the severity of structural pathologies.

\section{Types of surgery}

Surgery should aim to repair or reconstruct the pathological, structural lesions. Whether the approach is via open or arthroscopic surgery is less important. Almost all procedures can be performed via either route, with pros and cons depending on the surgeon, facilities and techniques.

\section{Anterior instability surgery}

Most capsulo-labral injuries without bony involvement and rotator cuff tears are repaired with suture anchors arthroscopically. Results are excellent in rugby players, without 'major' capsulo-labral lesions, such as HAGL and bony Bankart injuries.

Small, acute bony Bankart lesions can be successfully repaired if performed within 3 months of the original injury $[28,34,38]$. Chronic bony Bankart lesions have a high failure rate with direct repair, and a reconstructive procedure is recommended $[34,38]$. 
Table 1 Minor and major pathological lesions

\begin{tabular}{ll}
\hline Major lesions & Minor lesions \\
\hline Bony Bankart & Labral tear \\
Full-thickness rotator cuff tear & Partial-thickness rotator cuff tear \\
Large Hill-Sachs lesion & Small Hill-Sachs lesion \\
HAGL tear & \\
\hline
\end{tabular}

Table 2 Instability severity index score (ISIS) [5]

\begin{tabular}{lc}
\hline Prognostic factor & Score \\
\hline Age at surgery (years) & 2 \\
$\leq 20$ & 0 \\
$>20$ & \\
Glenoid loss of contour on AP radiograph & 2 \\
Loss of contour & 0 \\
No loss of contour & \\
Hill-Sachs lesion on external rotation AP radiograph & 2 \\
Visible & 0 \\
Not visible & \\
Degree of sports participation & 2 \\
Competitive & 0 \\
Recreational or none & \\
Type of sport & 1 \\
Contact or forced overhead & 0 \\
Other & \\
Shoulder hyperlaxity & 1 \\
Present & 0 \\
Not present & \\
Total & \\
\hline
\end{tabular}

HAGL tears are impossible to repair arthroscopically in the acute scenario, due to fluid extravasation. Arthroscopic repair of chronic HAGL tears is possible, but less likely to be successful in collision athletes [23]. Reconstructive surgery, in the form of the Latarjet procedure, is generally preferred.

\section{Latarjet procedure}

Chronic bony Bankart lesions progress to anterior bony glenoid deficiency with repeated instability. In rugby players, a bony reconstruction with coracoid transfer and sling effect of the modified Latarjet procedure is increasingly popular [5]. The degree of bony glenoid deficiency in isolation for Latarjet procedure is approximately $20 \%$ glenoid bone loss. However, in a collision athlete, any degree of bone loss is significant, considering the forces involved and associated injuries. The instability severity index score (ISIS) [3] is a useful clinical tool to use for decision-making for a Latarjet procedure in athletes. It takes into account and highlights the patient's age, hyperlaxity, glenoid bone involvement, Hill-Sachs lesion and level of sports participation (Table 2). It has been independently validated [33, 36], with a score of 4 and above indicative of a high failure rate of arthroscopic Bankart repairs.

\section{Posterior instability surgery}

Posterior labral involvement is more frequent in collision athletes than non-athletes [40]. It is more difficult to detect clinically as posterior instability generally presents with pain and clicking (subclinical) rather than true dislocation. Posterior labral tears are also more difficult to detect on imaging than Bankart tears, with a sensitivity under $60 \%$, but specificity of over $90 \%$ [19]. Surgical repair can be more challenging than anterior repairs, but the principles are the same, with excellent results in rugby players without glenoid bone loss [2]. In cases of posterior glenoid bone loss with instability, posterior glenoid bone reconstruction with autograft, combined with capsulo-labral repair, may be required.

\section{Rehabilitation}

The aim of rehabilitation after injury or surgery is to return the athlete to their previous level of sport as quickly and safely as possible. Adequate tissue healing to withstand the forces of the sport is required before returning safely to play. Our current basis for tissue healing times is inferred from experimental studies on laboratory animals and skin healing. Healing and recovery of an elite athlete may be a lot quicker than that, but currently we have no good way of measuring it. Traditionally, surgeons have used a timebased approach from empirical knowledge. As long as the surgical fixation is strong, the repair does not undergo undue strain within comfortable ranges of motion. The integrity of repairs should be tested on table determining a 'safe-zone' that therapists can use as a guide for postoperative safe, early motion. Only where there is a tendon repair, limit early active and resisted exercises. Elite athletes tend to have better conditioning, muscles and healing capacity than non-athletes. They also have a much higher level of therapy input, good supervision and motivation to be compliant with the rehabilitation process.

A goal-based, customised programme for return to sport after shoulder surgery is preferred [27]. This is shown in Table 3. The rehabilitation should be player-specific and tailored to suit the player's age, position, requirements, surgeon and therapists. It is not 'accelerated' or 'aggressive' or 'time-specific'. It is also surgeon-specific and dependent on the quality and type of fixation achieved. Therefore, the protocol is a 'guide' and not a prescription. Communication between the player, therapists, training staff and surgeon 
Table 3 Rugby-specific rehabilitation programme

\begin{tabular}{|c|c|}
\hline Phase 1 & Level 1-2 exercises \\
\hline Safe range of motion & Active assisted and progress to active motion in safe zone (as determined at surgery) \\
\hline Safe joint loading & Isometrics, closed chain work, scapular exercises, proximal trunk activation \\
\hline $\begin{array}{l}\text { Fitness and condition- } \\
\text { ing }\end{array}$ & $\begin{array}{l}\text { Able to bike immediately } \\
\text { No upper limb weights } \\
\text { Run in water (hydropool) } \\
\text { Short runs on treadmill as comfortable }\end{array}$ \\
\hline Sports-specific & Ball-to-hand passing in safe zone with rugby ball \\
\hline Phase 2 & Commence when completed phase 1 (usually 3 weeks post-op). Level 2-3 exercises \\
\hline Range of motion & Progress to full active range of motion as comfortable, no stretching \\
\hline Joint loading & $\begin{array}{l}\text { Open chain exercises with good glenohumeral joint control through range, rotator cuff exercises through pain free } \\
\text { range, graded resistance isometric/concentric } \\
\text { Strength: push/pull movements e.g. bench/seated row }\end{array}$ \\
\hline Sports-specific & Increase ball-to-hand passing, light perturbation training \\
\hline Phase 3 & When completed phase 2 (usually 6 weeks post-op). Level $3+$ exercises \\
\hline Range of motion & $\begin{array}{l}\text { Eccentric posterior to the scapula plane } \\
\text { Gently push lateral rotation if still stiff }\end{array}$ \\
\hline Joint loading & $\begin{array}{l}\text { Commence upper limb weights with conditioning coach } \\
\text { Approx } 50 \% \text { pre-op strength bench press/shoulder press } \\
\text { Scapula plane abduction } 50 \% \text { LSI } \\
\text { Proprioception: single arm prone hold } 50 \% \text { LSI; two point kneel on wobble cushion } 75 \% \text { LSI } \\
\text { Swimming freestyle if no risk of impingement }\end{array}$ \\
\hline Sports-specific & $\begin{array}{l}\text { Specific perturbation training exercises } \\
\text { General skills passing, fending to specifics, throwing in, scrum half pass, catching the high ball etc. }\end{array}$ \\
\hline Phase 4 & Usually at 8 weeks post-op \\
\hline Joint loading & Once $75 \%$ pre-op strength bench/shoulder press/chin up/dumbell row $=$ Commence power lifting/plyometrics \\
\hline Sports-specific & $\begin{array}{l}\text { Begin conditioning games and short training games } \\
\text { Controlled Tackling/scrumming/lineout lifting (usually } 10-16 \text { weeks) }\end{array}$ \\
\hline Phase 5 & $\begin{array}{l}\text { Return to play (usually } 12-16 \text { weeks) } \\
\text { Graduated return to play } \\
\text { Goals: } \\
\text { Regained full pre-op strength in weights } \\
\text { RC strength } 90 \% \text { LSI. Objective assessment e.g. isokinetics } \\
\text { Proprioception } R=L\end{array}$ \\
\hline
\end{tabular}

LSI limb symmetry index - percentage comparison of an activity to the opposite side; exercise levels are based on Funk et al. [14]

are essential, with progression to each phase when the patient is able to perform all of the exercises in the previous phase without any discomfort or apprehension. Each phase is introduced progressively.

\section{Return to play}

The decision to return to full sport is based on the achievement of the sport-specific goals and dependant on a number of factors that influence the risk of recurrent injury. The decision model of Creighton et al. [9] is a useful guide to assisting and understanding and optimising this process. The three-step decision-based model comprises health status, participation risk and decision modification. This is demonstrated in Fig. 4.
Step 1, Health Risk: the health status of the athlete is assessed through the evaluation of medical factors related to how much healing has occurred. This is often based on clinical signs, imaging and the ability to achieve specific functional tests.

Step 2, Participation Risk: the clinician evaluates the participation risk associated with participation, which is informed by not only the current health status but also by the sport risk modifiers (e.g. ability to protect the injury with padding, athlete position). Different individuals are expected to have different thresholds for "acceptable level of risk", and these thresholds will change based on context.

Step 3, Decision Modification: decision modifiers, such as timing and season, club and athlete pressures, are considered and the decision to return to play or not is made. 
Fig. 4 Return to play decision model [40]

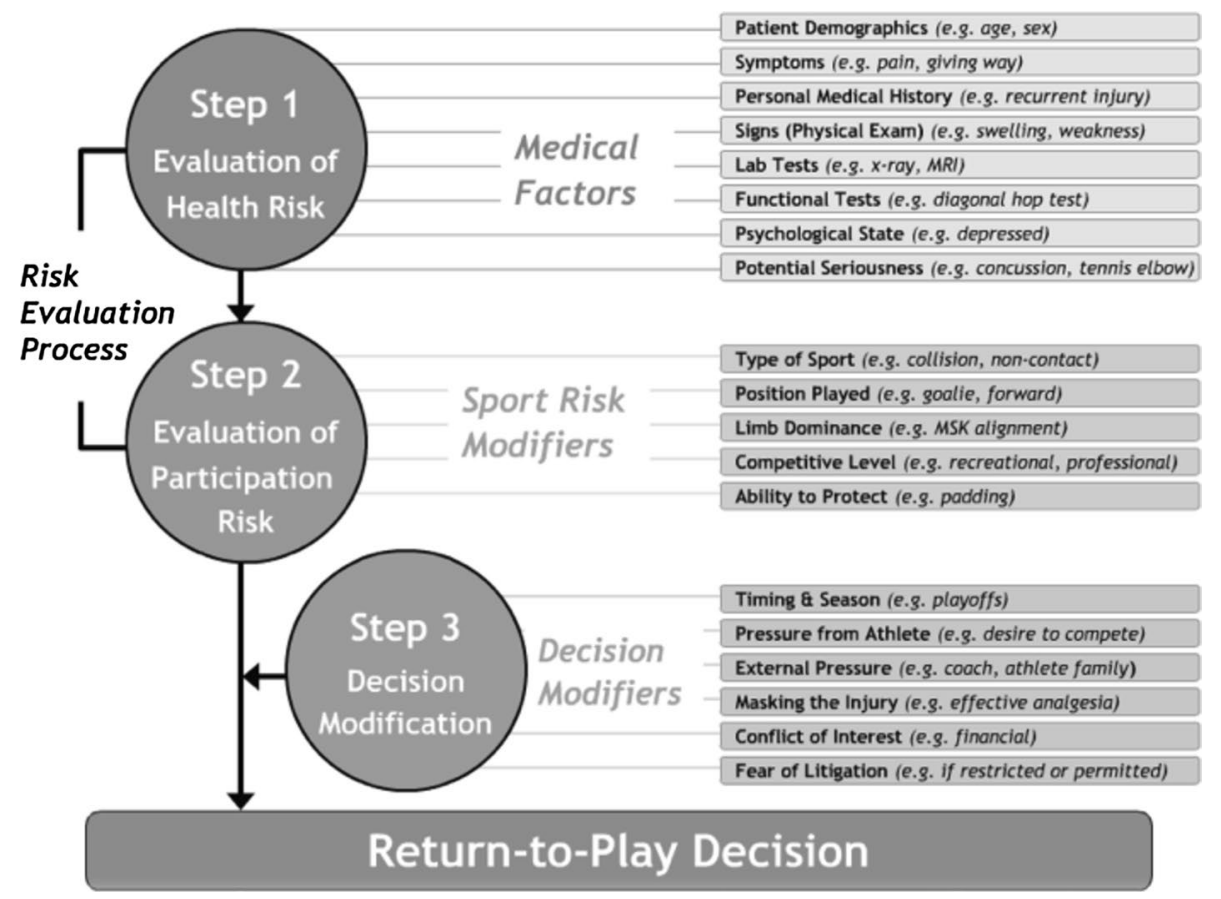

\section{Conclusion}

There is a range of severity of degree of instability, direction and structural injuries in rugby. These are generally consistent and predictable based on an understanding of the injury mechanism, targeted examination and relevant imaging. The decision to operate is based on number of clinical and sportsspecific factors. The decision on when to operate may be influenced by external factors. Therefore, the management of the rugby player with shoulder instability is often multidisciplinary and multifactorial. In this article, the current evidence and experience have been summarised to aide clinicians managing a collision athlete with shoulder instability, but each injured athlete should be managed as an individual.

Open Access This article is distributed under the terms of the Creative Commons Attribution 4.0 International License (http://creativecommons.org/licenses/by/4.0/), which permits unrestricted use, distribution, and reproduction in any medium, provided you give appropriate credit to the original author(s) and the source, provide a link to the Creative Commons license, and indicate if changes were made.

\section{References}

1. Arciero RA, Wheeler JH, Ryan JB, McBride JT (1994) Arthroscopic Bankart repair versus nonoperative treatment for acute, initial anterior shoulder dislocations. Am J Sports Med 22(5):589-594

2. Badge R, Tambe A, Funk L (2009) Arthroscopic isolated posterior labral repair in rugby players. Int J Shoulder Surg 3(1):4
3. Balg F, Boileau P (2009) The instability severity index score (ISIS score): a rational approach for patient selection in arthroscopic Bankart repair. J Bone Joint Surg 91(SUPP II):242

4. Beighton PH, Solomon L, Soskilne CL (1973) Articular mobility in an African population. Ann Rheum Dis 32(5):413

5. Burkhart SS, De Beer JF (2000) Traumatic glenohumeral bone defects and their relationship to failure of arthroscopic Bankart repairs: significance of the inverted-pear glenoid and the humeral engaging Hill-Sachs lesion. Arthroscopy 16(7):677-694

6. Burris MW, Johnson DL, Mair SD (2007) Management of inseason anterior shoulder dislocation in the amateur athlete. Orthop N J 30(5):362

7. Cheng SC, Sivardeen ZK, Wallace WA, Buchanan D, Hulse D, Fairbairn KJ, Kemp SP, Brooks JH (2012) Shoulder instability in professional rugby players - the significance of shoulder laxity. Clin J Sports Med 22(5):397-402

8. Cho NS, Hwang JC, Rhee YG (2006) Arthroscopic stabilization in anterior shoulder instability: collision athletes versus noncollision athletes. Arthroscopy 22(9):947-953

9. Creighton DW, Shrier I, Shultz R, Meeuwisse WH, Matheson GO (2010) Return-to-play in sport: a decision-based model. Clin J Sports Med 20(5):379-385

10. Crichton J, Doug RJ, Funk L (2012) Mechanisms of traumatic shoulder injury in elite rugby players. Br J Sports Med 46:7538-7542

11. de Beer J, Bhatia DN (1999) Shoulder injuries in rugby players. Int J Shoulder Surg 23(1):1-3

12. Dickens JF, Owens BD, Cameron KL, Kilcoyne K, Allred CD, Svoboda SJ, Sullivan R, Tokish JM, Peck KY, Rue JP (2014) Return to play and recurrent instability after in-season anterior shoulder instability a prospective multicenter study. Am J Sports Med 42(12):2842-2850

13. Fuller CW, Brooks JH, Cancea RJ, Hall J, Kemp SP (2007) Contact events in rugby union and their propensity to cause injury. Br J Sports Med 41(12):862-867 
14. Funk L, Tatlow K, Leftley C, Gibson J (2008) Shoulderdoc: shoulder exercise book. Shoulderdoc Ltd., Manchester. ISBN 9780956139603

15. Gagey OJ, Gagey N (2001) The hyperabduction test an assessment of the laxity of the inferior glenohumeral ligament. J Bone Joint Surg (Br) 83(1):69-74

16. Gissane C, Jennings DC, Standing $P$ (1993) Incidence of injury in rugby league football. Physiotherapy 79(5):305-310

17. Haseler CM, Carmont MR, England M (2010) The epidemiology of injuries in english youth community rugby union. Br J Sports Med 44(15):1093-1099

18. Headey J, Brooks JHM, Kemp SP (2007) The epidemiology of shoulder injuries in english professional rugby union. Am J Sports Med 9:1537-1543

19. Kalson NS, Geoghegan JM, Funk L (2011) Magnetic resonance arthrogram and arthroscopy of the shoulder: a comparative retrospective study with emphasis on posterior labral lesions and radiologist locality. Shoulder Elbow 3(4):210-214

20. Kibler WB, Sciascia AD, Hester P, Dome D, Jacobs C (2009) Clinical utility of traditional and new tests in the diagnosis of biceps tendon injuries and superior labrum anterior and posterior lesions in the shoulder. Am J Sports Med 37(9):1840-1847

21. Kim SH, Park JS, Jeong WK, Shin SK (2005) The Kim test a novel test for posteroinferior labral lesion of the shoulder-a comparison to the jerk test. Am J Sports Med 33(8):1188-1192

22. Kralinger FS, Golser K, Wischatta R, Wambacher M, Sperner G (2002) Predicting recurrence after primary anterior shoulder dislocation. Am J Sports Med 30(1):116-120

23. Kropf EJ, Tjoumakaris FP, Sekiya JK (2007) Arthroscopic shoulder stabilization: Is there ever a need to open? Arthroscopy 23(7):779-784

24. Larrain MV, Montenegro HJ, Mauas DM, Collazo CC, Pavón F (2006) Arthroscopic management of traumatic anterior shoulder instability in collision athletes: analysis of 204 cases with a 4-to 9-year follow-up and results with the suture anchor technique. Arthroscopy 22(12):1283-1289

25. Lebus GF, Raynor MB, Nwosu SK, Wagstrom E, Jani SS, Carey JL, Hettrich CM, Cox CL, Kuhn JE, MOON Shoulder Group (2015) Predictors for surgery in shoulder instability a retrospective cohort study using the feds system. Orth J Sports Med 3(10):2325967115607434

26. Mazzocca AD, Brown FM, Carreira DS, Hayden J, Romeo AA (2005) Arthroscopic anterior shoulder stabilization of collision and contact athletes. Am J Sports Med 33(1):52-60

27. Mcdonough A, Funk L (2011) Critical reflection of the advanced rehabilitation of an elite rugby league player sustaining a posterior Bankart lesion. Phys Ther Sport 14(1):60-67

28. Millett PJ, Braun S (2009) The "bony Bankart bridge" procedure: a new arthroscopic technique for reduction and internal fixation of a bony Bankart lesion. Arthroscopy 25(1):102-105
29. Neyton L, Young A, Dawidziak B, Visona E, Hager JP, Fournier Y, Walch G (2012) Surgical treatment of anterior instability in rugby union players: clinical and radiographic results of the Latarjet-Patte procedure with minimum 5-year follow-up. J Shoulder Elbow Surg 21(12):1721-1727

30. Olds M, Ellis R, Donaldson K, Parmar P, Kersten P (2015) Risk factors which predispose first-time traumatic anterior shoulder dislocations to recurrent instability in adults: a systematic review and meta-analysis. Br J Sports Med 21:bjsports-2014

31. Owen JM, Boulter T, Walton M, Funk L, Mackenzie TA (2015) Reinterpretation of O'Brien test in posterior labral tears of the shoulder. Int J Shoulder Surg 9(1):6

32. Owens BD, Agel J, Mountcastle SB, Cameron KL, Nelson BJ (2009) Incidence of glenohumeral instability in collegiate athletics. Am J Sports Med 37(9):1750-1754

33. Phadnis J, Arnold C, Elmorsy A, Flannery M (2015) Utility of the instability severity index score in predicting failure after arthroscopic anterior stabilization of the shoulder. Am J Sports Med 43(8): 1983-1988

34. Porcellini G, Campi F, Paladini P (2002) Arthroscopic approach to acute bony Bankart lesion. Arthroscopy 18(7):764-769

35. Provencher MT, LeClere LE, King S, McDonald LS, Frank RM, Mologne TS, Ghodadra NS, Romeo AA (2011) Posterior Instability of the shoulder diagnosis and management. Am J Sports Med 39(4):874-886

36. Rouleau DM, Hébert-Davies J, Djahangiri A, Godbout V, Pelet S, Balg F (2013) Validation of the instability shoulder index score in a multicenter reliability study in 114 consecutive cases. Am J Sports Med 41(2):278-282

37. Salomonsson B, Von Heine A, Dahlborn M, Abbaszadegan H, Ahlström S, Dalén N, Lillkrona U (2010) Bony Bankart is a positive predictive factor after primary shoulder dislocation. Knee Surg Sports Traumatol Arthrosc 18(10):1425-1431

38. Shah N, Naderi N, Funk L (2009) Arthroscopic bony Bankart repair in contact athletes. In: Presented at the British elbow and Shoulder Society Conference

39. Stewart DR, Burden SB (2004) Does generalised ligamentous laxity increase seasonal incidence of injuries in male first division club rugby players? Br J Sports Med 38(4):457-460

40. Torrance E, Walton M, Monga P, Watts A, Funk L (2015) Posterior and combined shoulder instability in a sporting population. Shoulder Elbow 7:309-332

41. Tzannes A, Murrel GAC (2004) An assessment of the interexaminar reliability of tests for shoulder instability. J Shoulder Elbow Surg 13:18-23

42. Tzannes A, Paxinos A, Callanan M, Murrell GA (2004) An assessment of the interexaminer reliability of tests for shoulder instability. J Shoulder Elbow Surg 13(1):18-23 